Bangladesh J. Bot. 44(3): 385-389, 2015 (September)

\title{
SCANNING ELECTRON MICROSCOPIC STUDY ON FREEZING BEHAVIOUR OF TISSUE CELLS IN DORMANT BUD OF MULBERRY (MORUS SP.)
}

\author{
Ravish Choudhary ${ }^{*}$, SK Malik, Rekha Chaudhury, Digvender Pal, \\ Pravin Patil and KC Sharama ${ }^{1}$ \\ Tissue Culture and Cryopreservation Unit, National Bureau of Plant Genetic \\ Resources (NBPGR), New Delhi 110 012, India
}

Key words: Dormant bud, Mulberry, Scanning electron microscope, Deep supercooling

\begin{abstract}
The freezing behaviour studies of dormant buds, were examined, employing scanning electron microscopy (SEM) and light microscopy. The differences and effect of freezing behaviour on dormant buds were observed. The dormant bud primordia of several woody plant species avoid freezing injury by deep supercooling. By slow cooling $\left(5^{\circ} \mathrm{C} /\right.$ day $)$ of dormant buds to $-30^{\circ} \mathrm{C}$, all living cells in bud tissues exhibited distinct shrinkage without intracellular ice formation detectable by SEM. However, the recrystallization experiment of these slowly cooled tissue cells, which was done by further freezing of slowly cooled buds with liquid nitrogen (LN) and then rewarming to $-10^{\circ} \mathrm{C}$, confirmed that some of the cells in the apical meristem, area in which cells had thin walls and in which no extracellular ice accumulated, lost freezable water with slow cooling to $-30^{\circ} \mathrm{C}$, indicating adaptation of these cells by deep super cooling. Water in plant tissues will not supercool unless heterogeneous ice nucleating substances are absent and the spread of ice from adjacent tissue can be prevented. Deep supercooling could not occur in dormant bud primordia if xylem vessels formed a continuous conduit connecting the dormant bud primordia with the remainder of the plant. If xylem continuity was established, ice could propagate via the vascular system and nucleate the water within the primordia. It is concluded that no extracellular ice crystals accumulated in such tissues containing deep supercooling cells with thin cell walls.
\end{abstract}

\section{Introduction}

Trees in cold areas have developed mechanisms of resistance to freezing temperatures during winter (Levitt 1972). At near subzero temperatures, water in apoplastic spaces in tree freezes. However, cells have developed mechanisms to prevent water in the cells from freezing, since intracellular freezing is lethal for all living cells (Mazur 2004). Freezing resistance of tissue cells of trees in cold areas is very high compared with that of herbaceous plants (Sakai and Larcher 1987). Moreover, tissue cells in trees in cold areas have various freezing adaptation mechanisms, unlike cells in herbaceous plant tissues, which adapt to freezing essentially by one mechanism (Sakai and Larcher 1987). Dormant buds in any tree are known to adapt to subfreezing temperatures by extraorgan freezing (Sakai and Larcher 1987, Quamme 1995). In the process of extraorgan freezing, large masses of extracellular ice crystals that have developed by dehydration from bud tissue cells accumulate in specific areas out of the main tissues in dormant buds. Such local accumulation of large extracellular ice crystals in dormant buds is different to the random distribution of comparatively small extracellular ice crystals throughout the whole tissue adjacent to dehydrated cells in the usual process of extracellular freezing. It has been suggested that such extraorgan freezing in dormant buds may occur due to the sensitivity of some bud tissue cells to the presence of adjacent extracellular ice crystals during freezing-induced dehydration, which may

*Author for correspondence: <ravianu1110@gmail.com>. 'Department of Botany, University of Rajasthan, Jaipur-302004, India. 
cause intracellular freezing by ice inoculation (Sakai 1979, Ishikawa and Sakai 1981, Quamme et al. 1995, Kang et al. 1998). Thus, extraorgan freezing is a unique mechanism of adaptation to subfreezing temperatures in dormant buds of trees, but it does not mean freezing behaviour at the cellular level.

Xylem parenchyma cells of trees, on the other hand, adapt to subfreezing temperature by deep supercooling, a freezing adaptation mechanism that is completely different to that of extracellular freezing (Fujikawa and Kuroda 2000, Kuroda et al. 2003, Fujikawa et al. 2009). Xylem parenchyma cells have specifically thick with rigid cell walls, and the cell walls do not allow dehydration even in the presence of adjacent extracellular ice crystals. Consequently, in order to prevent lethal intracellular freezing without dehydration, xylem parenchyma cells have developed the ability to maintain a liquid state of intracellular water by supercooling even at very low temperatures and for long periods during winter (Fujikawa and Kuroda 2000, Fujikawa et al. 2009). The dormant buds exhibited typical extraorgan freezing. Extracellular ice crystals accumulated only in basal areas of scales and beneath crown tissues, areas in which only these living cells had thick walls unlike other tissue cells. By slow cooling $\left(5^{\circ} \mathrm{C} /\right.$ day $)$ of dormant buds to $-50^{\circ} \mathrm{C}$, all living cells in bud tissues exhibited distinct shrinkage without intracellular ice formation (Endoh et al. 2009). Ashworth (1984) examined the relationship to deep supercooling in dormant buds of six Prunus species and supported the hypothesis that the lack of xylem continuity is an important feature of buds which deep supercool. In the present study, freezing behaviour of dormant buds of mulberry after cryopreservation was studied using scanning electron microscopy and microtomy.

\section{Materials and Methods}

One-year-old twigs of mulberry (Morus sp.) with lengths of about $20 \mathrm{~cm}$ were collected in mid-winter (February 2011) from mature trees growing on the garden of NBPGR, New Delhi, India $\left(28^{\circ} 35^{\prime} \mathrm{N}, 70^{\circ} 18^{\prime} \mathrm{E}\right)$. The twigs were immediately placed in plastic bags to prevent desiccation and were preserved at a temperature of about $10^{\circ} \mathrm{C}$ for up to 6 months until use. Dormant buds were excised from twigs with a small part $(1 \mathrm{~mm})$ of each twig attached to the bud and used for experimental material.

Dormant buds of mulberry were desiccated in charged silica gel for $4-7 \mathrm{hrs}$ at room temperature. These desiccated buds were then used for cryopreservation in liquid nitrogen at $-196^{\circ} \mathrm{C}$ using slow freezing protocol (Niino et al. 1995). The two-step freezing was achieved by sequentially lowering the temperature at $-5^{\circ} \mathrm{C} /$ day up to terminal temperature of $-30^{\circ} \mathrm{C}$ before plunging in liquid nitrogen at $-196^{\circ} \mathrm{C}$. The desiccated buds were packed in $1.0 \mathrm{ml}$ polypropylene cryovials. These vials were shifted sequentially at $5,-5,-10,-15,-20$ and $-25^{\circ} \mathrm{C}$, and $-30^{\circ} \mathrm{C}$ keeping at each of the temperatures for a minimum of $24 \mathrm{hrs}$. The cryovials were held at $-30^{\circ} \mathrm{C}$ for $48 \mathrm{hrs}$ and then directly plunged in the liquid nitrogen at $-196^{\circ} \mathrm{C}$.

The dormant buds of mulberry carefully excised from the twigs with the help of sharp blade (no. 11) and cleaned the surface by washing with distilled water. Washed buds were fixed in $2.5 \%$ glutaraldehyde for $48 \mathrm{hrs}$ at room temperature in black screw cap glass bottles. The longitudinal sections were taken from hardy buds after fixation. The sections were transferred in $1 \mathrm{M}$ phosphate buffer $(\mathrm{pH}$ 7.4) for $1 \mathrm{hr}$ at room temperature after that washing was carried out with phosphate buffer thoroughly for 3 times. Dehydration of the buds was done by passing it through 30, 50, 70, 90 and 100\% acetone series for $1 \mathrm{hr}$ each. At the end, two changes in 100\% acetone were carried out. After fixation and dehydration, the dehydrated tissues were transferred in HMDS solution for $1 \mathrm{hr}$ for chemical drying. Dried buds were then mounted on aluminium stubs using double-sided adhesive tape. Buds were mounted on double sided carbon adhesive tape. The dried buds which 
were mounted on carbon tape on stubs were then transferred for gold coating in ion sputter coater. The dried specimen and metal-coated stubs were then stored in desiccator to avoid re-absorption of moisture from the air. Metal-coated stubs were loaded into the specimen chamber (vacuum vessel) of scanning electron microscope (JEOL, JSM-A 840). The specimens were scanned and desired images were photographed.

Descaled buds were fixed in formalin-acetic acid-alcohol (FAA) for $24 \mathrm{hrs}$ at room temperature in vacuum condition. The fixed buds were preserved in $70 \%$ ethanol and dehydrated through tertiary butyl alcohol (TBA) series and embedded in paraffin. Longitudinal sections were cut on a rotary microtome (Liaca, RM 2165). Sections were cut at $10 \mu \mathrm{m}$ in thickness. Haupt's adhesive (Johansen, 1940) was used for affixing the paraffin ribbons to the slides. These sections were stained with safranin and fast green combinations (Johansen 1940). Stained slides were cleared in xylene and mounted in DPX mountant. Measurements and photographs of the sections were taken using light microscopy.

\section{Results and Discussion}

The structure of dormant buds of mulberry before and after cryopreservation was observed by SEM (Fig. 1 A, B, D, E). The dormant buds of all the three species were covered by several layers of scales and leaf primordium in which an apical dome was present. The results showed that all of the living cells were rich in water showing formation of numerous small intracellular ice crystals in the freeze-fractured cytoplasm. The size of intracellular ice crystals was larger in cells of basal areas of scales than those in cells of the leaf primordium and shoot primordium including apical dome. Fresh and cryopreserved buds using two-step freezing revealed that ice crystallization did not appear in most of the cells (Fig. 1C). However, the buds were cryopreserved directly without two-step freezing; ice crystals within the basal areas of scales were observed (Fig. 1F).
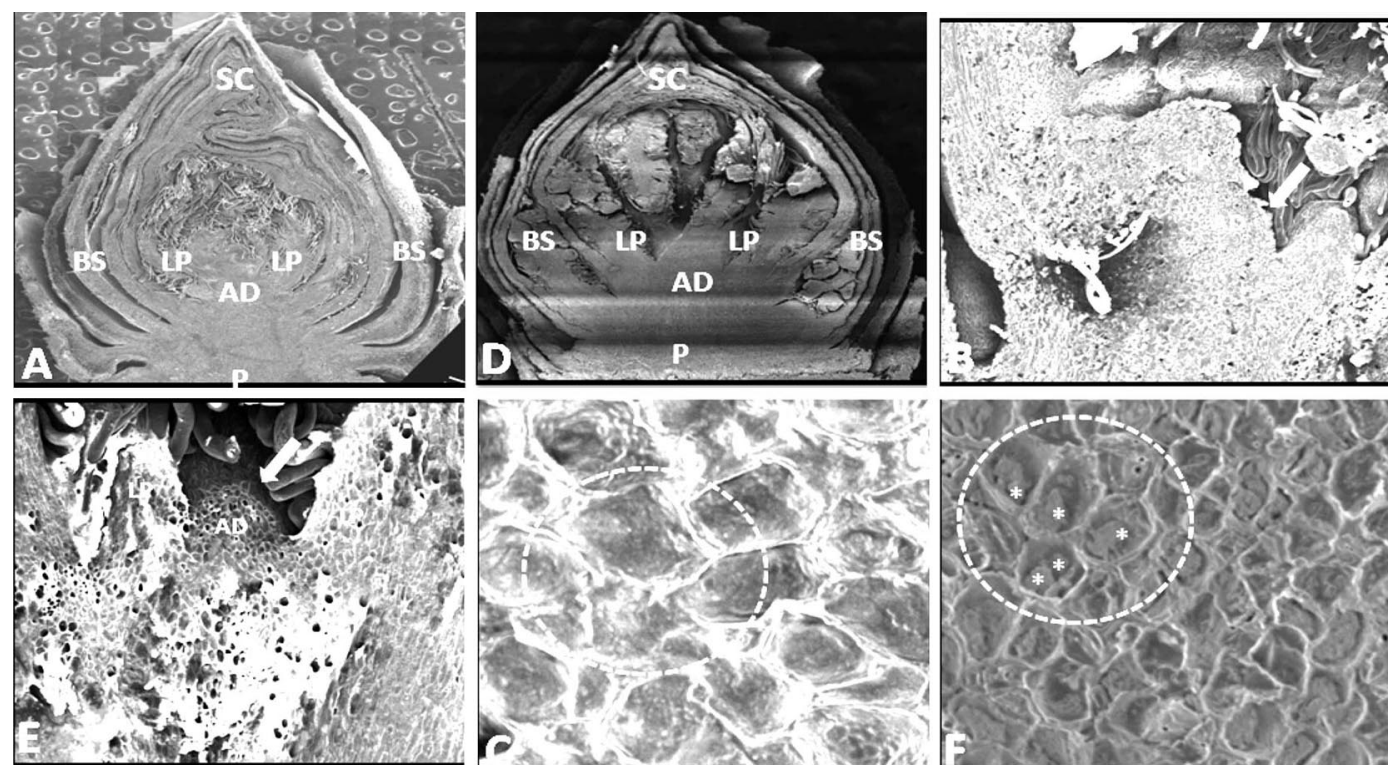

Fig. 1. SEM photographs showing a longitudinal section of the whole dormant bud of mulberry (A, B) before cryo, (D, E) after cryo. Cells in basal area of scales (C) before cryo, showing without intracellular ice crystals (surrounded by dotted circle) and (F) shrunken cells with intracellular ice crystals (*surrounded by dotted circle). SC- scales; BS- basal areas of scale; LP- leaf primordium, AD- apical dome. 
The structure of dormant buds of mulberry was observed by thin sectioning with a light microscope (Fig. 2 A). The dormant bud was enveloped by several layers of scales, contained several leaf primordia and a shoot apex in which an apical dome existed at the top (Fig. 2 A). The apical dome was covered with scales and leaf primordia. The bud was connected to a twig with pith and xylem. Cells in the apical dome of the cryopreserved dormant buds showed shrinking (Fig. 2 B) due to the removal of water.
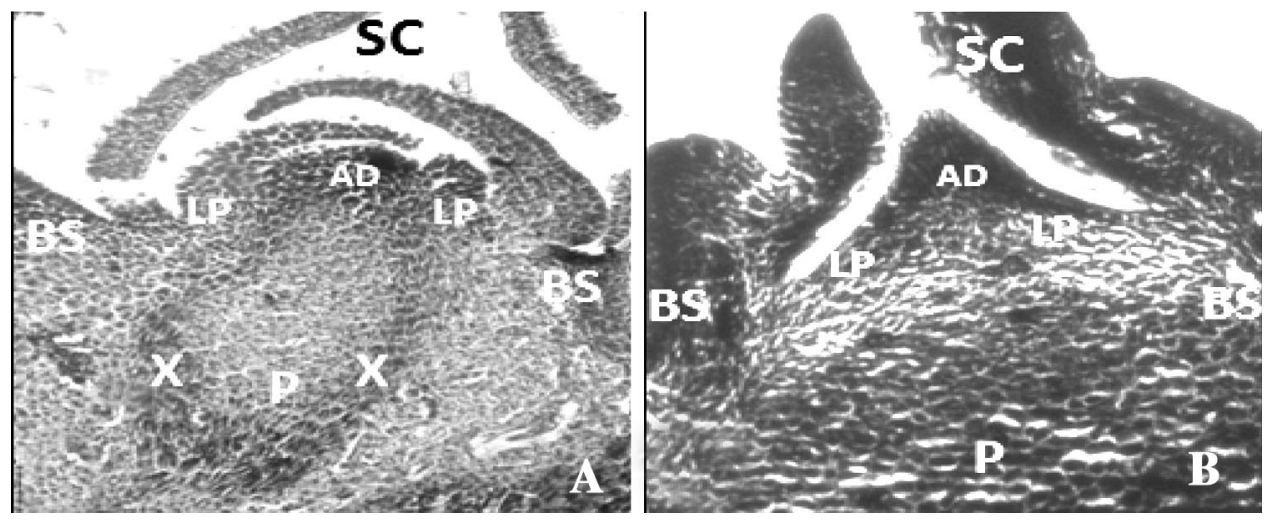

Fig. 2. Longitudinal view of dormant buds of mulberry (A) before cryo and (B) after cryo; SC- scales; BSbasal areas of scale; LP - leaf primordium, AD - apical dome, P - pith and X - xylem.

Anatomical studies by Ashworth (1982) revealed that dormant peach flower buds demonstrated that the primordia did not contain xylem vessel elements. The present study supports the hypothesis that the lack of xylem continuity between the primordia and adjacent tissues of mulberry buds is an important feature of buds which supercool. There is a relationship between the lack of vascular continuity and deep supercooling was observed (Ashworth and Rowse 1982). The results of these studies led to the proposal that the lack of xylem continuity between the dormant primordia and the remainder of the plant was an important feature permitting buds to deep supercool (Ashworth 1982, Ashworth and Rowse 1982). The establishment of xylem continuity would provide a conduit for the spread of ice into the bud primordia and would lead to the irreversible loss of the capacity to deep supercool. Further investigation will be required for the study of dormant buds.

Extracellular ice crystals were observed in basal areas of scales after direct cryopreservation in dormant buds. However, buds were cryopreserved after two-step freezing, ice crystallization did not occur. Similar results were obtained by Endoh et al. (2009). They also described that ice crystals accumulated only in basal areas of scales, where all the living cells had thick walls. It was noted that cells in the areas in which ice accumulated, i.e., basal areas of scales and had thick walls, whereas cells in other areas in which no extracellular ice accumulated, i.e., apical dome and leaf primordium, had thin walls. It has been suggested that such extraorgan freezing in dormant buds may occur due to the sensitivity of some bud tissue cells to the presence of adjacent extracellular ice crystals during freezing-induced dehydration, which may cause intracellular freezing by ice inoculation (Sakai 1979, Ishikawa and Sakai 1981, Quamme et al. 1995, Kang et al. 1998). This view is in agreement with the present research. 


\section{Acknowledgements}

Authors are very thankful to the Director, National Bureau of Plant Genetic Resources (NBPGR), New Delhi for encouragement and financial support.

\section{References}

Ashworth EN 1982. Properties of peach flower buds which facilitate supercooling. Plant Physiol. 70: $1475-1479$.

Ashworth EN 1984. Xylem development in Prunus flower buds and the relationship to deep supercooling. Plant Physiol. 74: 862-865.

Ashworth EN and Rowse DJ 1982. Vascular development in dormant Prunus flower buds and its relationship to supercooling. Hort. Sci. 17: 790-791.

Endoh K, Kasuga J, Arakawa K, Ito T and Fujikawa S 2009. Cryo-scanning electron microscopic study on freezing behaviours of tissue cells in dormant buds of larch (Larix kaempferi). Cryobio. 59: 214-222.

Fujikawa S and Kuroda K 2000. Cryo-scanning electron microscopic study on freezing behaviour of xylem ray parenchyma cells in hardwood species. Micron 31: 669-686.

Fujikawa S, Kasuga J, Takata N and Arakawa K 2009. Factors related to change of deep supercooling capability in xylem parenchyma cells of trees, In: Gusta LV, Wisniewski M, Tanino M, eds., Plant Cold Hardiness: From the Laboratory to the Field, CABI Press, Wallingford, UK. pp. 29-42.

Ishikawa M and Sakai A 1981. Freezing avoidance mechanisms by supercooling in some Rhododendron flower buds with reference to water relations. Plant Cell Physiol. 22: 953-967.

Johansen D A 1940. Plant Microtechnique. McGraw-Hill, Book Co., New York and London.

Kang K S, Motosugi H, Yonemori K and Sugiura A 1998. Supercooling characteristics of some deciduous fruit trees as related to water movement within the bud. J. Hort. Sci. Biotech. 73: 165-172.

Kuroda K, Kasuga J, Arakawa K and Fujikawa S 2003. Xylem ray parenchyma cells in boreal hardwood species respond to subfreezing temperatures by deep supercooling that is accompanied by incomplete desiccation. Plant Physiol. 131: 736-744.

Levitt J 1972. Physiological Ecology: Responses of the plants to environmental stress, freezing injury, freezing resistance and molecular basis of freezing injury and tolerance. Academic Press, London. pp. 61-109 and 188-228.

Mazur P 2004. Principles of cryobiology. In: Fuller BJ, Lane N, Benson EE eds., Life in the Frozen State., CRC Press, Boca Raton. pp. 3-65.

Niino T, Shirata K and Oka S 1995 . Viability of mulberry winter buds cryopreserved for 5 years at $-135^{\circ} \mathrm{C}$. J. Seri. Sci. Japan 64: 370-374.

Quamme HA 1995. Deep supercooling in buds of woody plants. In: Lee RE, Warren GJ, Gusta LV eds., Biological Ice Nucleation and Its Applications, APS Press, St. Paul, MN. pp. 183-199.

Quamme HA, Su WA and Veto LJ 1995. Anatomical features facilitating supercooling of the flower within the dormant peach flower bud. J. Amer. Soc. Hort. Sci. 120: 814-822.

Sakai A 1979. Deep supercooling in winter flower buds of Cornus florida L. Hort. Sci. 14: 69-70.

Sakai A and Larcher W 1987. Frost Survival of Plants: Responses and Adaptation to Freezing Stress, Springer-Verlag, Berlin. 